\title{
Management and Control of a DC Bus Powered by Renewable Energies
}

\author{
Mouhamadou Moustapha Diop¹, Ibrahima Gueye¹, Abdoulaye Kebé2, Moustapha Diop ${ }^{1}$ \\ ${ }^{1}$ ENSETP, Dakar, Senegal \\ ${ }^{2}$ Cheik Anta Diop University of Dakar (UCAD), Dakar, Senegal \\ Email: mouhamadoumoustapha6.diop@ucad.edu.sn
}

How to cite this paper: Diop, M.M., Gueye, I., Kebé, A. and Diop, M. (2021) Management and Control of a DC Bus Powered by Renewable Energies. Journal of Applied Mathematics and Physics, 9, 1652-1672.

https://doi.org/10.4236/jamp.2021.97111

Received: April 7, 2021

Accepted: July 24, 2021

Published: July 27, 2021

Copyright (c) 2021 by author(s) and Scientific Research Publishing Inc. This work is licensed under the Creative Commons Attribution International License (CC BY 4.0).

http://creativecommons.org/licenses/by/4.0/

\begin{abstract}
This article proposes a method of management and control of a continuous bus powered by renewable energies for autonomous applications. The DC bus is obtained from two systems of renewable sources (the solar system and the wind system) and storage battery (Lithium Ion). The continuous bus control and management procedure require efficiency in the control of the charge and discharge of the battery according to the load energy demand (DC Motor). The battery charging process is non-linear, varying over time with considerable delay, so it is difficult to achieve the best performance on control with energy management using traditional control approaches. A fuzzy control strategy is used in this article for battery control. To improve battery life, fuzzy control manages the desired state of charge (SOC). The entire system designed is modeled and simulated on MATLAB/Simulink Environment.
\end{abstract}

\section{Keywords}

DC Bus, Battery Lithium Ion, Control and Management, Lifetime, SOC, Fuzzy Logic, DC Motor

\section{Introduction}

With increased awareness of the depletion of energy sources and the environmental damage caused by the increase in $\mathrm{CO}_{2}$ emissions in the exploitation of carbon in electricity, the use of renewable energies is mandatory [1] (P. Chiradeja, Dec. 2004). The combination of multi-renewable energy sources and storage systems provides a user-friendly alternative environment for stand-alone operations [2] (M. H. Nehrir, Oct. 2011). However, there are several challenges with the hybrid power system: configurations, control strategies and management between various elements are necessary to achieve optimum power. 
Due to the intermittence of renewables, the use of storage systems like batteries is inevitable to compensate for fluctuations in energy production [3] (Jeroen Tant, January 2013). First, wind power is used as a source to drive a turbine which in turn drives a generator. AC power is generated with variable frequency and unstable voltage, so it will be converted to direct current. Direct current is used either to serve the load directly or converted to AC to AC loads. Due to the uncertainties on the availability of renewable energies, battery storage is adopted. Thus electrical energy will be stored in the battery when excessive power is produced and will still be supplied to the load as soon as the source produces less.

As we know, the successive charges and discharges of the battery reduce its lifetime. With such a system, the problem is to prove how and when the battery should be charged, provide good energy efficiency and increase its lifetime [4] (Yong Yin, 2008).

Fuzzy control is offered here to optimize power distribution and configure the battery state of charge (SOC). A control strategy based on fuzzy control allows us to satisfy the demand of the load according to the energy capacity of the source.

\section{Configuration of the DC Bus}

This part presents a system for controlling a continuous bus from three different sources, namely the wind turbine, photovoltaic source and a storage battery. For a better management of this hybrid system, it is important to establish the architecture of the configuration.

In a DC bus, architecture as shown in Figure 1, different renewable sources (wind-photovoltaic) and battery are connected to the DC bus through the appropriate electronic converters.

Alternating current loads can be connected to the DC Bus with inverter. Direct current loads can also be connected directly to the Bus with an amplifier

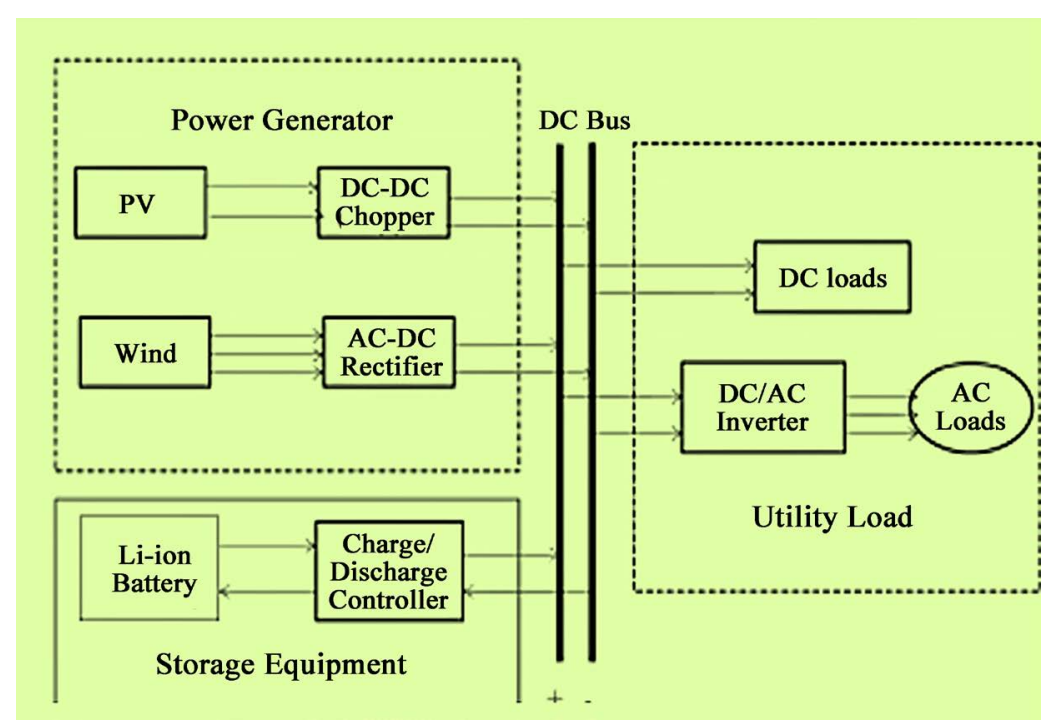

Figure 1. DC bus configuration. 
converter to obtain a voltage necessary for these loads.

The system (see Figure 1) can also supply power to AC loads or be interfaced to a power grid through a DC/AC converter designed to allow two-way flow of power.

\section{System Model}

To verify the correctness of the designed controller, a dynamic model of the proposed system is required. Each system will be modeled and simulated on MATLAB. The model of each subsystem is explained in detail below.

\subsection{Modeling of Solar Cell}

The equivalent diagram of the real photovoltaic module takes into account resistive effects. It consists a diode $(D)$, a current source $\left(I_{P h}\right)$ characterizing the Photo-current, a serie resistance $\left(R_{s}\right)$ representing the losses by effect Joule, and a Resistance Shunt $\left(R_{s h}\right)$ characterizing a leakage current between the upper grid and the rear contact which is generally much greater than $\left(R_{s}\right)$.

The output current of the photovoltaic module (see Figure 2) is as in the following mathematical form:

$I_{P V}=I_{P h}-I_{d}-I_{s h}$ With $I_{P h}, I_{d}, I_{s h}, I_{P V}$ are respectively the photonic current, the diode current, shunt resistance current and the operating current or (current delivered by the module), which depend on solar radiation and cell temperature. The current $I_{p h}$ is directly dependent on solar radiation $E$ and the temperature of the cell; it is given by the following relation.

$$
I_{P h}=P_{1} \cdot E_{1}\left[\left(1+P_{2}\right) \cdot\left(E-E_{r e f}\right)\right]+E_{1}\left(T_{j}-T_{r e f}\right)
$$

The cell temperature can be calculated from the ambient temperature and irradiation as follows:

$$
T_{j}=T_{a}+E(\text { Noct }-20 / 800)
$$

With:

Noct $=$ nominal operating temperature of the solar cell.

$T_{a}=$ ambient temperature.

And the diode current is:

$$
I_{d}=I_{s a t} \cdot \mathrm{e}^{\frac{q \cdot\left(V+R \cdot I_{p h}\right)}{A N_{S} \cdot K T_{j}}}
$$

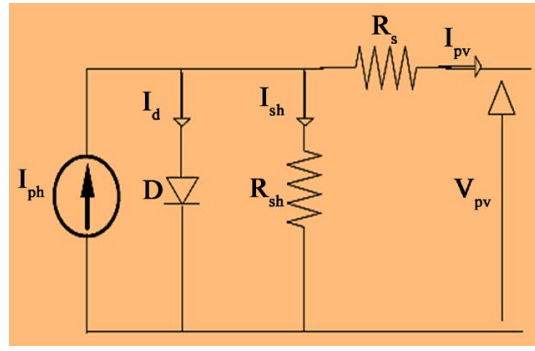

Figure 2. Solar panel equivalent circuit. 
With:

$I_{\text {sat }}=$ Diode saturation current;

$T_{j}=$ Cell temperature;

$A=$ diode quality constant;

$N_{s}$ : Serial cell number in a module;

$I_{\text {sat }}$ Saturation current, it dependent to the temperature, it is given by the following relation:

$$
I_{s a t}=P_{4} \cdot T_{J}^{3} \cdot \mathrm{e}^{-\frac{E_{g}}{K T_{j}}}
$$

The current of the shunt resistor is:

$$
I_{s h}=\frac{V_{P V}+R_{s} \cdot I_{P V}}{R_{S H}}
$$

The module current is

$$
\begin{gathered}
I_{P V}=I_{p h}(E, T)-I_{d}\left(v, I_{p v}, T_{j}\right)-I_{s h}(v) \\
\Leftrightarrow \\
I_{P V}=\left[P_{1} \cdot E\left(1+\left(P_{2} \cdot\left(E-E_{r e f}\right)\right)\right)\right]+\left[P_{3}\left(T_{j}-T_{r e f}\right)\right] \\
-\left[P_{4} T_{J}^{3} \cdot \mathrm{e}^{-\frac{E_{g}}{K T_{j}}}\right] \cdot\left[\mathrm{e}^{\left[q \cdot\left(V+R I_{P h}\right) / A N_{S} \cdot K T_{j}\right]}-1\right]-\left[\left(V_{P V}+R_{S} I_{P V}\right) / R_{s h}\right] \\
=5=1+3+4
\end{gathered}
$$

With:

$E_{\text {ref: }}$ Reference Irradiation $1000 \mathrm{~W} / \mathrm{m}^{2}$.

$T_{\text {ref }}$ Reference Temperature de $25^{\circ} \mathrm{C}$.

\section{BOOST Model}

DC-DC converter allows to regulate the transfer of energy from a DC source to the load with a high efficiency. Depending on the structure, it can be step-down or step-up and, under certain conditions, return energy to the power supply.

\section{1) BOOST (DC-DC)}

Figure 3 is a DC-DC converter. The input source is of direct current type (inductor in series with a voltage source) and the output load is of direct voltage type (capacitor in parallel with the resistive load). Switch (K) can be replaced by a transistor because the current is always positive and the switching operations

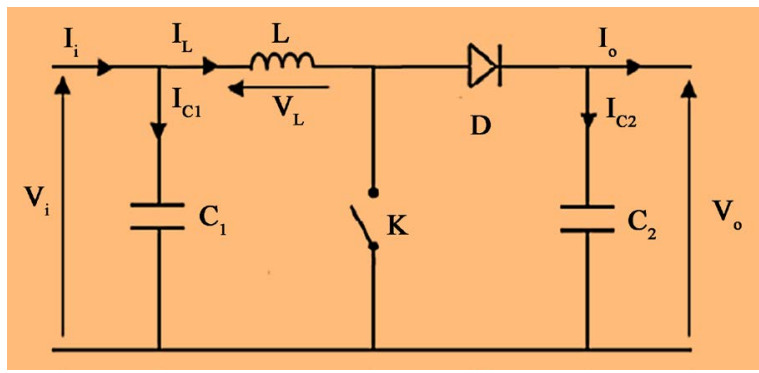

Figure 3. Electrical Boost equivalent circuit. 
must be controlled (on blocking and on starting).

\section{2) Mathematical Boost Model}

In order to be able to synthesize the functions of the booster chopper in the equilibrium state, it is necessary to present the equivalent circuit diagrams at each position of $\mathrm{K}$. that of Figure 4 presents the equivalent circuit of the boost when $\mathrm{K}$ is closed between $[0, \alpha T]$.

Kirchhoff allows (refer to Figure 4):

$$
\begin{gathered}
I_{C_{1}}(t)=C_{1} \frac{\mathrm{d} V_{i}(t)}{\mathrm{d} t}=\left[I_{i}(t)-I_{L}(t)\right] \\
I_{C_{2}}(t)=C_{2} \frac{\mathrm{d} V_{0}(t)}{\mathrm{d} t}=-I_{0}(t) \\
V_{L}(t)=L \frac{\mathrm{d} I_{l}(t)}{\mathrm{d} t}=V_{i}(t)
\end{gathered}
$$

Circuit equivalent while $\mathrm{K}$ is opened:

By refer to Figure 5

$$
\begin{aligned}
& I_{C_{1}}(t)=C_{1} \frac{\mathrm{d} C_{i}(t)}{\mathrm{d} t}=\left[I_{i}(t)-I_{L}(t)\right] \\
& I_{C_{2}}(t)=C_{2} \frac{\mathrm{d} V_{0}(t)}{\mathrm{d} t}=\left[I_{L}(t)-I_{0}(t)\right] \\
& V_{L}(t)=L \frac{\mathrm{d} I_{L}(t)}{\mathrm{d} t}=\left[V_{I}(t)-V_{O}(t)\right]
\end{aligned}
$$

\subsection{Wind Modeling Tribune}

\subsubsection{Wind Model}

Wind power is defined as:

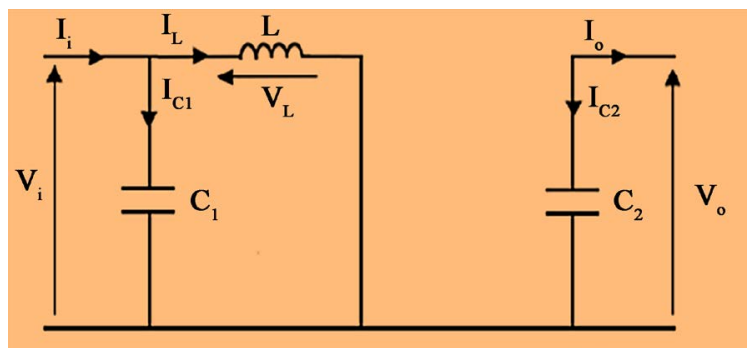

Figure 4. BOOST while $\mathrm{K}$ is close.

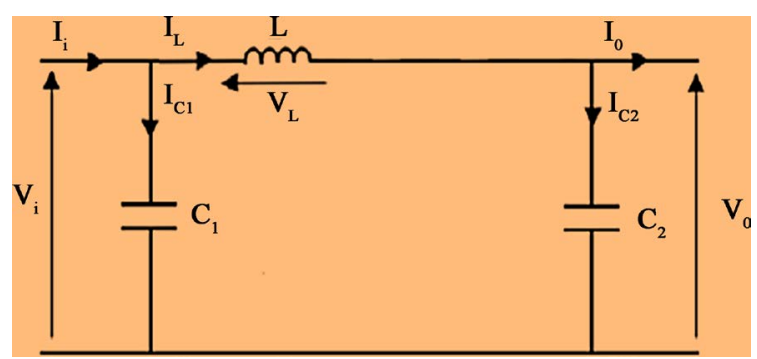

Figure 5. Boost while $\mathrm{K}$ is opened. 


$$
P_{v}=\frac{1}{2} \ell \cdot S \cdot V^{3}
$$

The most interesting wind gives as speed 6 to $10 \mathrm{~m} / \mathrm{s}$ [5] (A. Mirecky, 2005).

\subsubsection{Tribune Model}

The classic wind system is composed of a wind turbine which transforms wind energy into mechanical energy, the device studied here is a wind turbine comprising blades of radius $\mathrm{R}$ driven by the wind and which in turn drive the generator [6] (L. Khetache, 2007).

The aerodynamic power appearing at the rotor is:

$$
P_{t}=C_{p} \cdot P_{v}=C_{p} \cdot\left[\frac{1}{2} \ell \cdot S \cdot V^{3}\right]
$$

The aerodynamic torque is:

$$
C_{t}=\frac{P_{t}}{\Omega_{t}} \frac{C_{p} \cdot\left[\frac{1}{2} \ell \cdot S \cdot V^{3}\right]}{' \Omega_{t}}
$$

\subsubsection{Torque Dynamic Equation}

$$
C_{e m}=\frac{P}{\omega}\left[\left(E_{a} \cdot i_{a}+E_{b} \cdot i_{b}+E_{c} \cdot i_{c}\right)\right]
$$

With:

$P$ : Number of poles.

$\omega$ : Rotor Speed: $\omega=P \cdot{ }^{\prime} \Omega_{t}$

$E_{a, b, c}:$ stator force electromotive.

$i_{a, b, c}:$ Phase current.

For the machine, we can either use the synchronous or asynchronous machine. For our study we move on to the modeling the two machines.

\subsubsection{Asynchronous Motor Modeling}

MAS presents very complicated phenomena which intervene in its operation, such as magnetic saturation, eddy current, etc. Therefore, some simplifying assumptions are assumed to establish simple relationships between the motor's supply voltages and its currents.

The winding is distributed so as to give an magneto motor force sinusoidal if supplied by sinusoidal currents.

We will also assume that we are working in an unsaturated regime.

We neglect the phenomenon of hysteresis, eddy current, skin effect and notch effect.

The zero sequence regime is zero because the neutral is not connected to the earth.

$$
\frac{\mathrm{d} I_{s q}}{\mathrm{~d} t}=\frac{1}{\sigma L_{s}}\left[V_{s q}-I_{s q}\left(R_{s}+\frac{L_{m}^{2}}{L_{r} T_{r}}\right)+\frac{L_{m}}{L_{r}} \omega \varnothing_{r q}+\frac{L_{m}}{L_{r} T_{r}} \varnothing_{r d}+\omega_{s} I_{s d} \sigma L_{s}\right]
$$




$$
\begin{aligned}
\frac{\mathrm{d} \varnothing_{r d}}{\mathrm{~d} t} & =\left[\frac{L_{m}}{T_{r}} I_{s d}\right]-\left[\frac{1}{T_{r}} \varnothing_{r d}\right]+\left[\left(\omega_{s}-\omega\right) \varnothing_{r q}\right] \\
\frac{\mathrm{d} \varnothing_{r d}}{\mathrm{~d} t} & =\left[\frac{L_{m}}{T_{r}} I_{s d}\right]-\left[\frac{1}{T_{r}} \varnothing_{r d}\right]+\left[\left(\omega_{s}-\omega\right) \varnothing_{r q}\right] \\
\frac{\mathrm{d} \omega}{\mathrm{d} t} & =\left[\frac{P^{2}}{J} \frac{L_{m}}{L_{r}} \cdot\left(\varnothing_{r d} I_{s q}-\varnothing_{r q} I_{s d}\right)\right]-\frac{P}{J} C_{r}
\end{aligned}
$$

\subsubsection{Synchronous Motor Modeling}

By the same analogy while taking into account the flux of permanent magnets.

$$
\begin{gathered}
\frac{\mathrm{d} I_{d}}{\mathrm{~d} t}=\frac{-R}{L} I_{d}+P \omega I_{q}+\frac{1}{L} V_{d} \\
\frac{\mathrm{d} I_{q}}{\mathrm{~d} t}=\frac{-R}{L} I_{q}+P \omega I_{d}+\frac{\Phi_{f}}{L} P \omega+\frac{1}{L} V_{q} \\
\frac{\mathrm{d} \omega}{\mathrm{d} t}=\frac{3 P}{2 J} \Phi_{f} \cdot I_{q}-\frac{1}{j} T_{l}-\frac{B}{J} \omega \\
T_{e m}=\frac{3 P}{2}\left(\Phi_{f} \cdot I_{q}\right)
\end{gathered}
$$

With: $B, J$ and $T_{I}$ define the damping coefficient, the moment of inertia of the rotor and the load torque.

\subsection{Battery Modeling}

\section{CIEMAT Model Battery}

This model, studied by Olivier GERGAUD, is based on the diagram in Figure 6 which represents the equivalent diagram of number elements in series. The battery is represented in this case by a voltage source and an internal resistance.

The equation of the voltage $V_{\text {bat }}$ can therefore be written:

$$
V_{b a t}=n_{b}\left[E_{b}\right]+n_{b}\left[R_{i} I_{b a t}\right]
$$

where $V_{b a t}$ and $I_{b a t}$ are respectively the voltage and current values of the battery in Receiver Convention, $E_{b}$ represents the emf of the battery which depends on the state of charge and $R_{i}$ is the internal resistance of a cell.

The equation of state charge is:

$$
\mathrm{EDC}=\left[1-\frac{Q_{d}}{C_{b a t}}\right]
$$

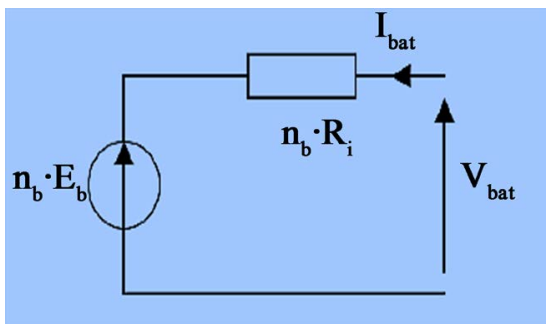

Figure 6. Equivalent circuit of CIEMAT model battery. 
The amount of missing charge $Q_{d}$ depends on the operating mode of the battery, it increases during charging and decreases during discharge.

The equation for the discharge voltage is given by (Gergaud O., 2002):

$$
\begin{aligned}
V_{b a t-d}= & {\left[n_{b} \cdot(1.965+0.12 \cdot \mathrm{EDC})\right] } \\
& -n_{b} \cdot \frac{\left|I_{\text {bat }}\right|}{C_{10}} \cdot\left[\left(\frac{4}{1+\left|I_{\text {bat }}\right|^{1.3}}+\frac{0.27}{\mathrm{EDC}^{1.5}}+0.02\right) \cdot(1-0.007 \cdot \Delta T)\right]
\end{aligned}
$$

where $C_{10}$ the battery capacity in A.h at constant current discharge is for 10 hours, and $\Delta T$ is the temperature deviation of the accumulator from a reference temperature of $25^{\circ} \mathrm{C}$.

L'expression de la charge est exprimée par:

$$
\begin{aligned}
V_{\text {bat }-C}= & {\left[n_{b} \cdot(2+0.16 \cdot \mathrm{EDC})\right] } \\
& +n_{b} \cdot \frac{\left|I_{\text {bat }}\right|}{C_{10}} \cdot\left[\left(\frac{6}{1+\left|I_{\text {bat }}\right|^{0.86}}+\frac{0.48}{1-\mathrm{EDC}^{1.2}}+0.36\right) \cdot(1-0.025 \cdot \Delta T)\right]
\end{aligned}
$$

\section{Energy Management by Fuzzy Logic}

The energy management system controls the amount of energy flow between the different components in order: wind, so and battery.

To meet the load demand, efficient management of energy exchanges between different components and allows a significant increase in efficiency. The use of renewable energy sources leading to a reduction in pollution.

An effective management of energy exchanges between various components allows significant increase in efficiency.

The system configuration consists three blocks see Figure 7.

The solar panel system, the wind system and the lithium-ion battery. The photovoltaic system and wind power are non-linear systems and the fuzzy logic controller offers a convenient way to design a non-linear control system.

The design of these systems is necessary to maintain maximum power.

The difference between the actual power and the power generated is taken to charge and discharge the lithium-ion battery. Battery life and SOC (charge and discharge rate) depend on the battery charge and discharge time. To improve its lifetime, the fuzzy controller keeps the battery SOC at the desired level.

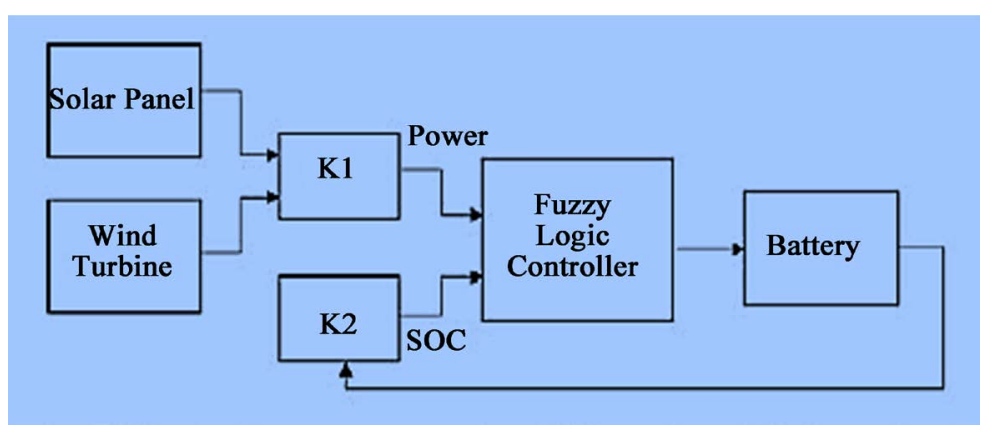

Figure 7. Management system by fuzzy logic. 


\section{Battery Management Using Fuzzy Logic Controller}

In this article, a lithium ion battery was used as an energy storage device. Comparing different types of batteries, lithium-ion battery has a longer service life, which is why it is chosen here. To achieve the desired SOC, the fuzzy controller is designed for regulation. The input of the fuzzy logic is $\Delta \mathrm{SOC}$ and $\Delta P$, and the output is the variable current $\Delta I$ (see Figure 8 and Figure 9).

$$
\begin{gathered}
\Delta \mathrm{SOC}=\Delta \mathrm{SOC}_{\text {commande }}-\mathrm{SOC}_{\text {new }} \text { and } \\
\Delta P=P_{L}-\left(P_{\text {wind }}+P_{p v}\right)
\end{gathered}
$$

The energy produced comes from the energy of solar panels and wind power. The total power is the difference between the load power and the power generated by the wind turbine and the solar panel. The entry and exit membership
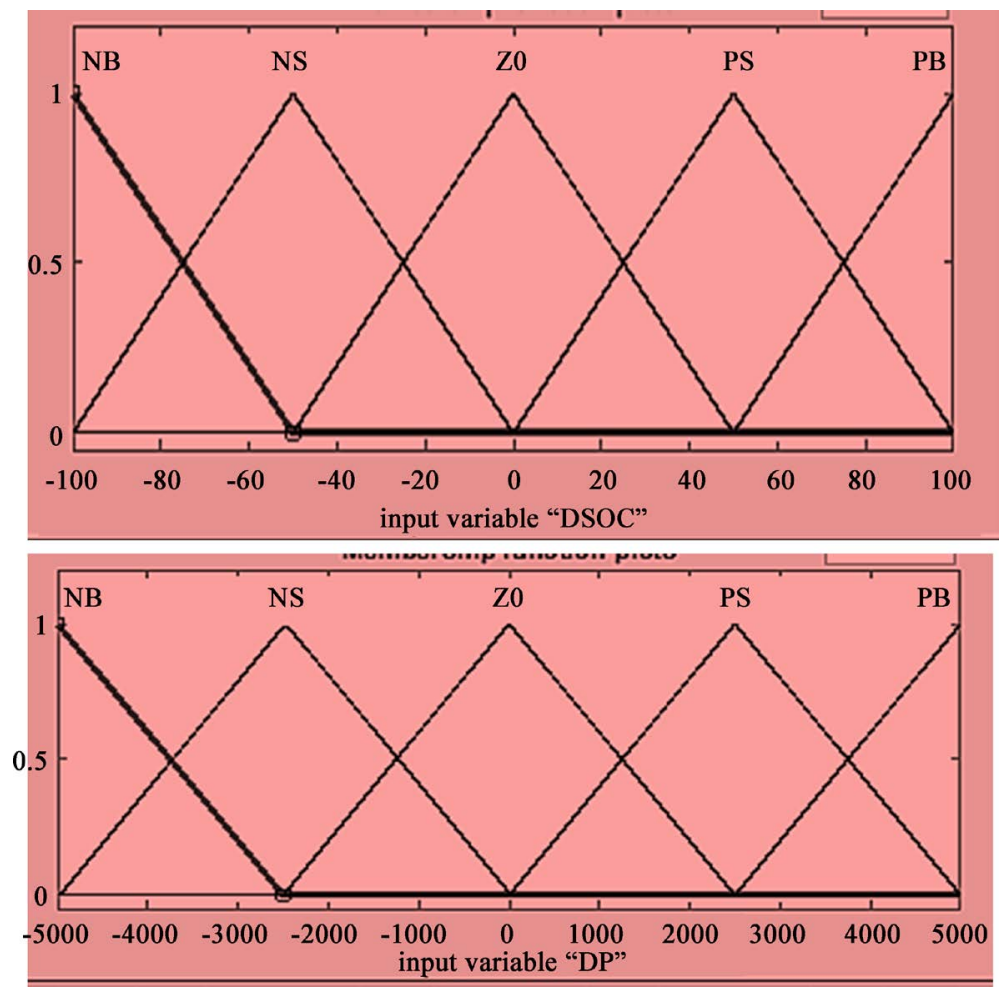

Figure 8. Input membership functions.

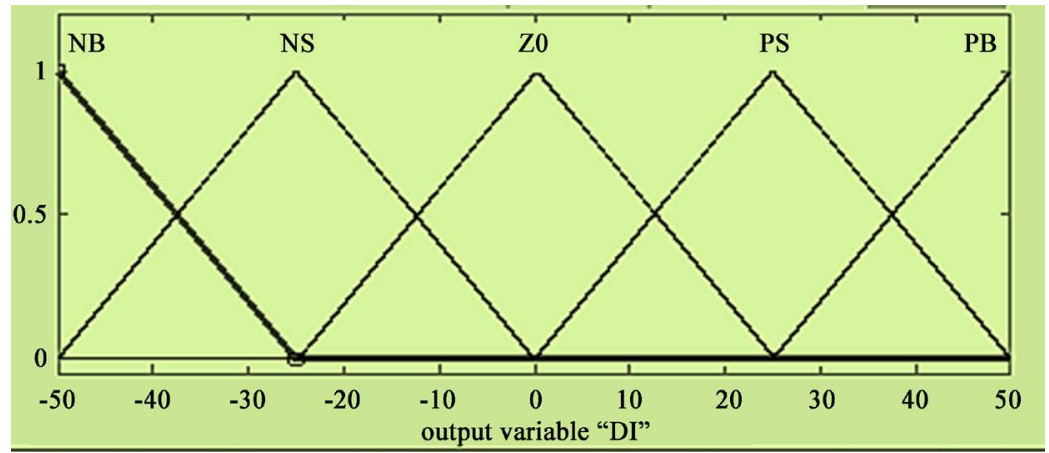

Figure 9. Output membership of variable $\Delta I$. 
function contains five grades:

NB (negative Big), NS (negative small), ZO (zero), PS (positive small), PB (positive big).

We can determine the membership function and replace it with a scale factor to get SOC charge and discharge. If the power is negative, the renewable energy system satisfies the load demand and the fuzzy controller forces the battery to charge.

If the $\triangle \mathrm{SOC}$ is negative, it means that the SOC of the battery is higher than the SOC of demand. Thus, the battery should operate in discharge mode.

The state of the battery is based on the difference between the power of the source and the power of the load.

The difference between the SOC state and the controlling SOC directly determines the battery mode.

Table 1 shows the fuzzy rules of our system. For example when the variable input $\mathrm{P}$ is $\mathrm{NB}$ and $\triangle \mathrm{SOC}$ is $\mathrm{NB}$, the output I becomes $\mathrm{PB}$. The control SOC applied to fuzzy control is $50 \%$. If the SOC of the battery is less than the SOC of the control, the battery remains in a state of charge. Otherwise the battery is discharged. To extend battery life, fuzzy control rules are set to keep the SOC of the battery above $45 \%$ [7] (K. H. M. Tech, 2014).

\section{Load Control (DC Motor)}

The speed of the DC motor is regulated with a closed loop speed controller using feedback from the tachometer.

It is possible, however, to control the speed of the DC motor without tachometer feedback.

Figure 10 shows a speed control circuit which drives a DC motor at a speed proportional to a voltage command, $V_{1 N}$. It does this by exploiting a basic characteristic of DC motors.

Proper speed control is achieved by adjusting the gain at the non-inverting input to compensate for the voltage drop across the winding resistor.

The motor is modeled as a series winding resistor $R_{M}$, and an inverse EMF generator. The operational amplifier circuit provides negative resistance control equal to the winding resistance.

Table 1. Fuzzy control rules.

\begin{tabular}{lllllll}
\hline \multicolumn{1}{c}{$\Delta \boldsymbol{I}$} & & & & $\Delta \boldsymbol{P}$ & & \\
\cline { 3 - 7 } & & NB & NS & ZO & PS & PB \\
\hline \multirow{4}{*}{$\Delta$ SOC } & NB & PB & PB & PB & PB & PB \\
& NS & PB & PB & PS & PS & PB \\
& ZO & ZO & ZO & ZO & PS & PB \\
& PS & NS & NS & NS & NS & PB \\
& PB & NB & NB & NB & NB & PB \\
\hline
\end{tabular}




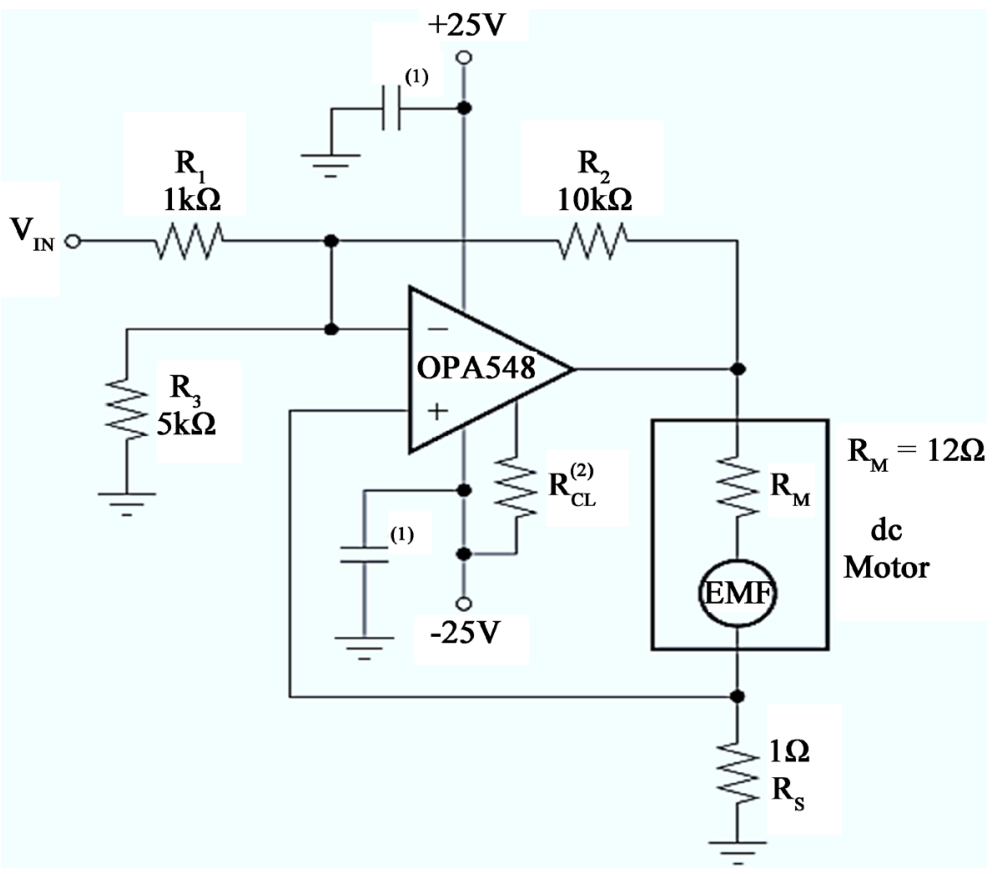

Figure 10. DC motor control.

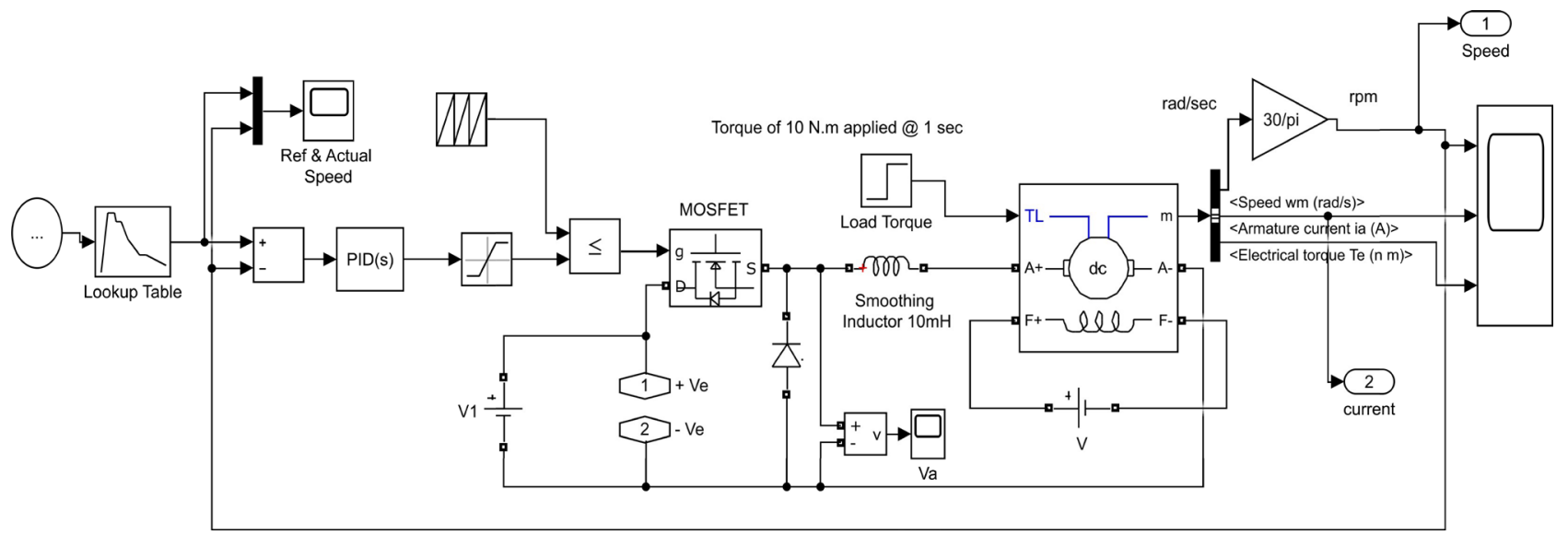

Figure 11. DC motor control model.

This causes the reverse electromagnetic force to be proportional to the control voltage input.

The speed and direction of the motor are determined by the magnitude and polarity of the control voltage.

This control technique is similar to the technique used on the simulation model.

The motor speed is always compared to a reference speed following a PID corrector. The signal at the output of the PID is then compared again to a sinusoidal carrier (see model in Figure 11).

\section{Parameters}

1) Cell parameters 


\begin{tabular}{|c|}
\hline Module type: Suntech STP270S-24_Vb \\
\hline Number of cells per module \\
\hline 72 \\
\hline Number of series-connected modules per string \\
\hline 2 \\
\hline Number of parallel strings \\
\hline 50 \\
\hline Module specifications under STC [ Voc, Isc, Vmp, Imp ] \\
\hline$\left[\begin{array}{lllll}44.4999 & 8.19978 & 35 & 7.70979\end{array}\right]$ \\
\hline Model parameters for 1 module [ Rs, Rp, Isat, Iph, Qd ] \\
\hline$\left[\begin{array}{lllll}0.32025 & 2562.3 & 8.8992 \mathrm{e}-07 & 8.2979 & 1.5\end{array}\right]$ \\
\hline
\end{tabular}

2) Parameters of synchronous motor

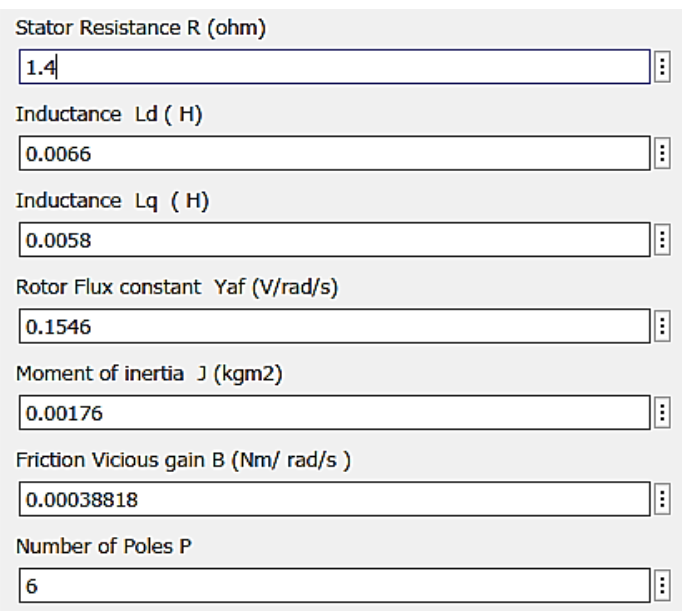

\section{3) Battery parameters}

\begin{tabular}{l} 
Type: Lithium-Ion \\
- Temperature- \\
$\square$ Simulate temperature effects \\
\hline Aging \\
$\square$ Simulate aging effects \\
Nominal voltage (V) 24 \\
Rated capacity (Ah) 100 \\
Initial state-of-charge (\%) 80 \\
Battery response time (s) 70
\end{tabular}

\section{4) Tribune parameters}

Nominal mechanical output power (W): 5000

Base power of the electrical generator (VA): $190 / .9$

Base wind speed $(\mathrm{m} / \mathrm{s}): 12$

Maximum power at base wind speed (pu of nominal mechanical power): 0.73

Base rotational speed (p.u. of base generator speed): 1.2

Pitch angle beta to display wind-turbine power characteristics (beta >=0) (deg): 0 


\section{Simulation Result}

\subsection{For Solar}

Figure 12 shows the characteristic $I_{P V}=f\left(V_{p v}\right)$ and $P_{p v}=f\left(V_{p v}\right)$ of the entire photovoltaic system for standard conditions of sunshine and temperature.

\subsubsection{Influence of Temperature}

Temperature is an important parameter in the behavior of cells. Figure 13 shows

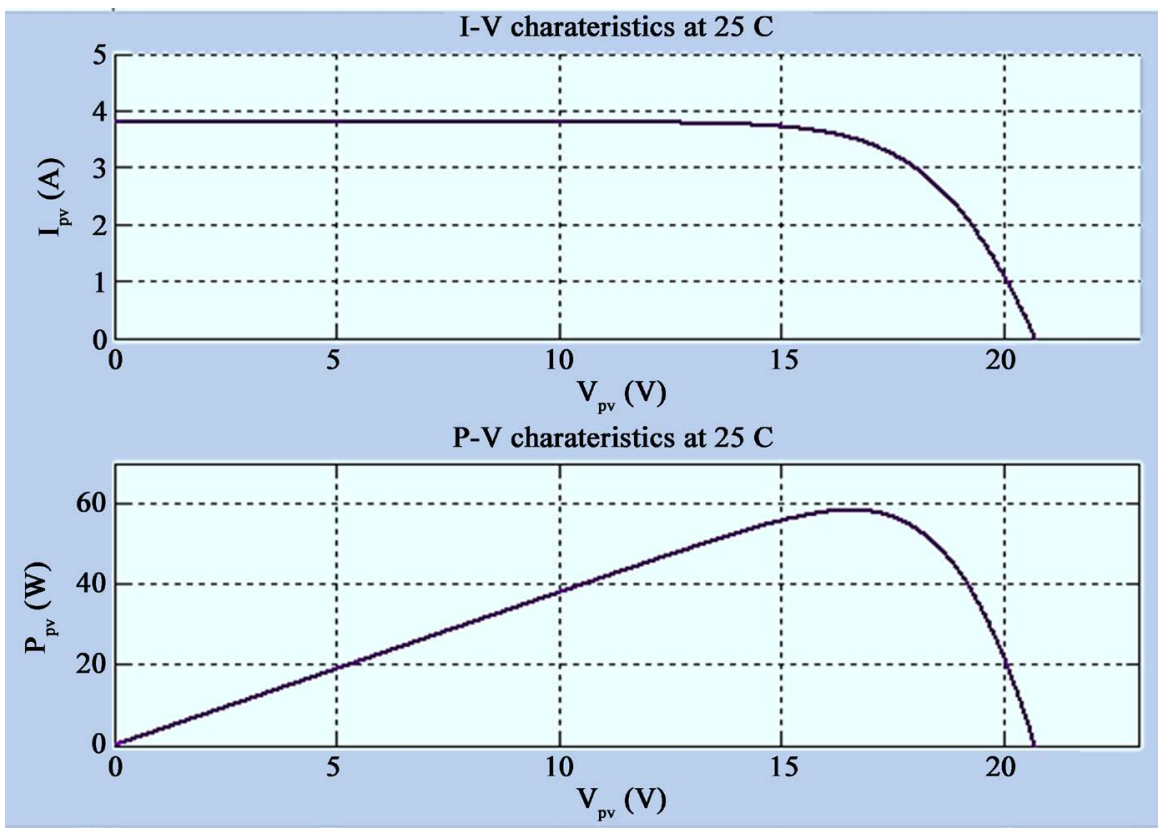

Figure 12. Characteristics of current and power as a function of voltage for $G=1000$ $\mathrm{W} / \mathrm{m}^{2}$ and $T c=25^{\circ} \mathrm{C}$.
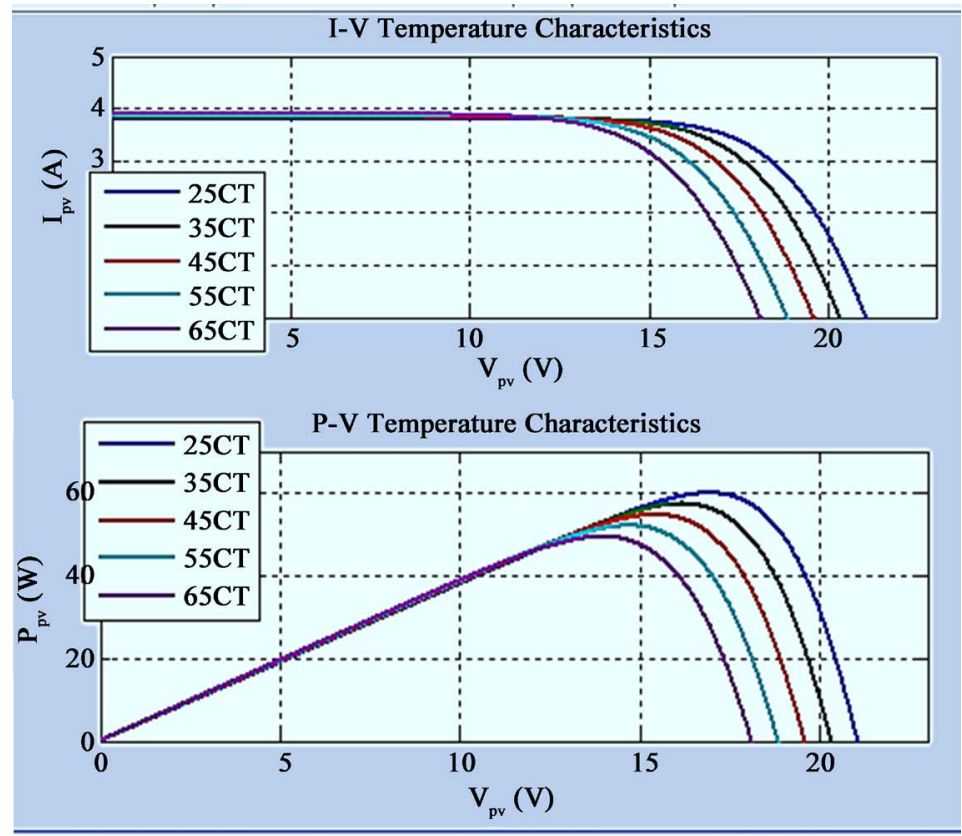

Figure 13. P-V Température characteristics and I-V temperature characteristic. 
that the increase in temperature results in a net decrease in open circuit voltage and a small increase in short-circuit current, as well as a decrease in maximum power.

\subsubsection{Irradiation Influence}

The increase in sunshine as in Figure 14, results in a displacement of the characteristic $I=f(V)$ along the axis of the currents. The increase of the short-circuit current is much greater than that of the open-circuit voltage since the short-circuit current is a linear function of the illuminance, while that of the open-circuit voltage is logarithmic.

The maximum power $P_{m}$ increases with increasing illuminance. However, the voltage points corresponding to the maximum power vary little, see Figure 15.

\subsection{Synchronous Machine Result}

\subsubsection{Mechanical Speed (See Figure 16)}

For a reference speed $\omega_{\text {ref }}=1200 \mathrm{rad} / \mathrm{s}$ under a load of fixed value. We see through

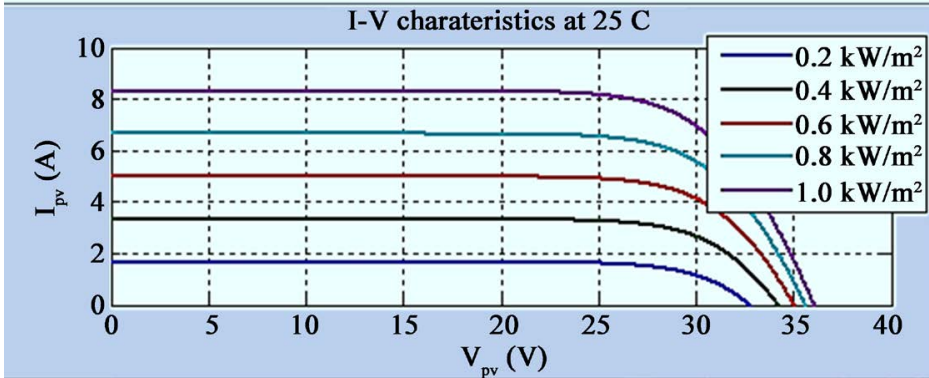

Figure 14 . I-V characteristics at $25^{\circ}$.

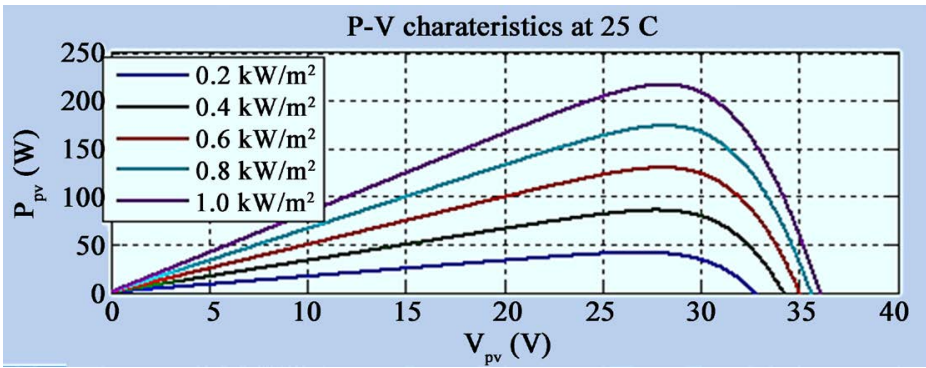

Figure 15. P-V characteristics at $25^{\circ}$.

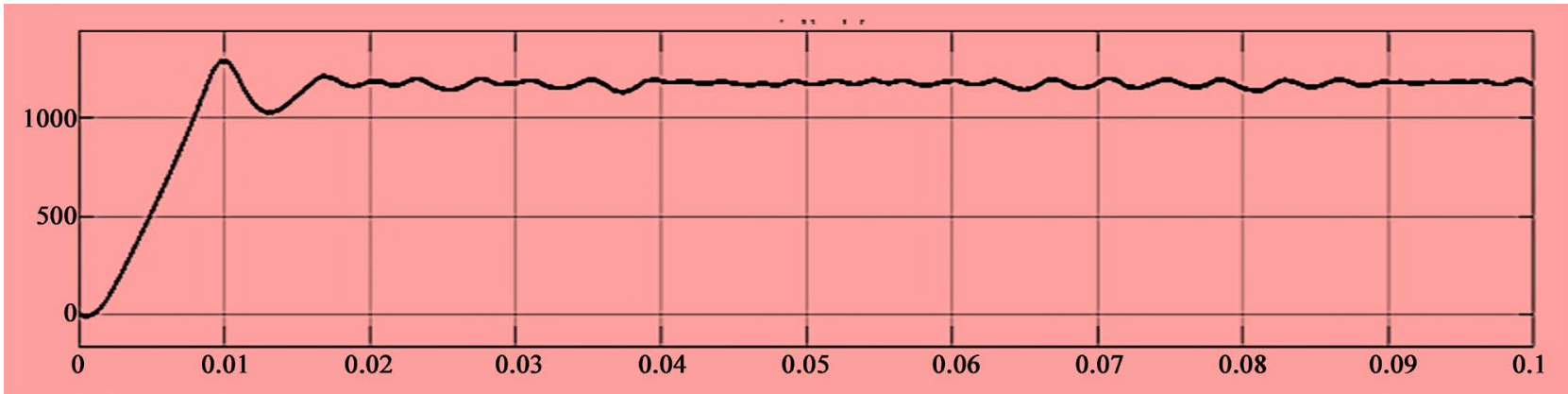

Figure 16. Mechanical speed. 
Figure 16, in the period from $t=0 \mathrm{~s}$ to $t=0.01 \mathrm{~s}$, that the speed varies proportionally for a fixed load, and this is quite normal given the linear relationship between the voltage and the speed. From $t=0.01 \mathrm{~s}$ until $t=0.1 \mathrm{~s}$ the speed is constant for $w=1200 \mathrm{rad} / \mathrm{s}$.

\subsubsection{Wind Synchronous Machine and Rectifier}

We impose our machine a wind speed of $12 \mathrm{~m} / \mathrm{s}$, a blade angle of 5 degrees and a generator speed of $1.2 \mathrm{rad} / \mathrm{s}$. An RLC load of $110 \mathrm{w}$ power is imposed on the system.

The rotor speed (Figure 17) increases independently of the rate of the electromechanical torque. The electromagnetic torque being negative indicates operation in generator mode. The torque value adapts with variations in speed and load depending on the power supplied.

\subsection{Battery Results}

\subsubsection{Battery Source (Figure 18)}
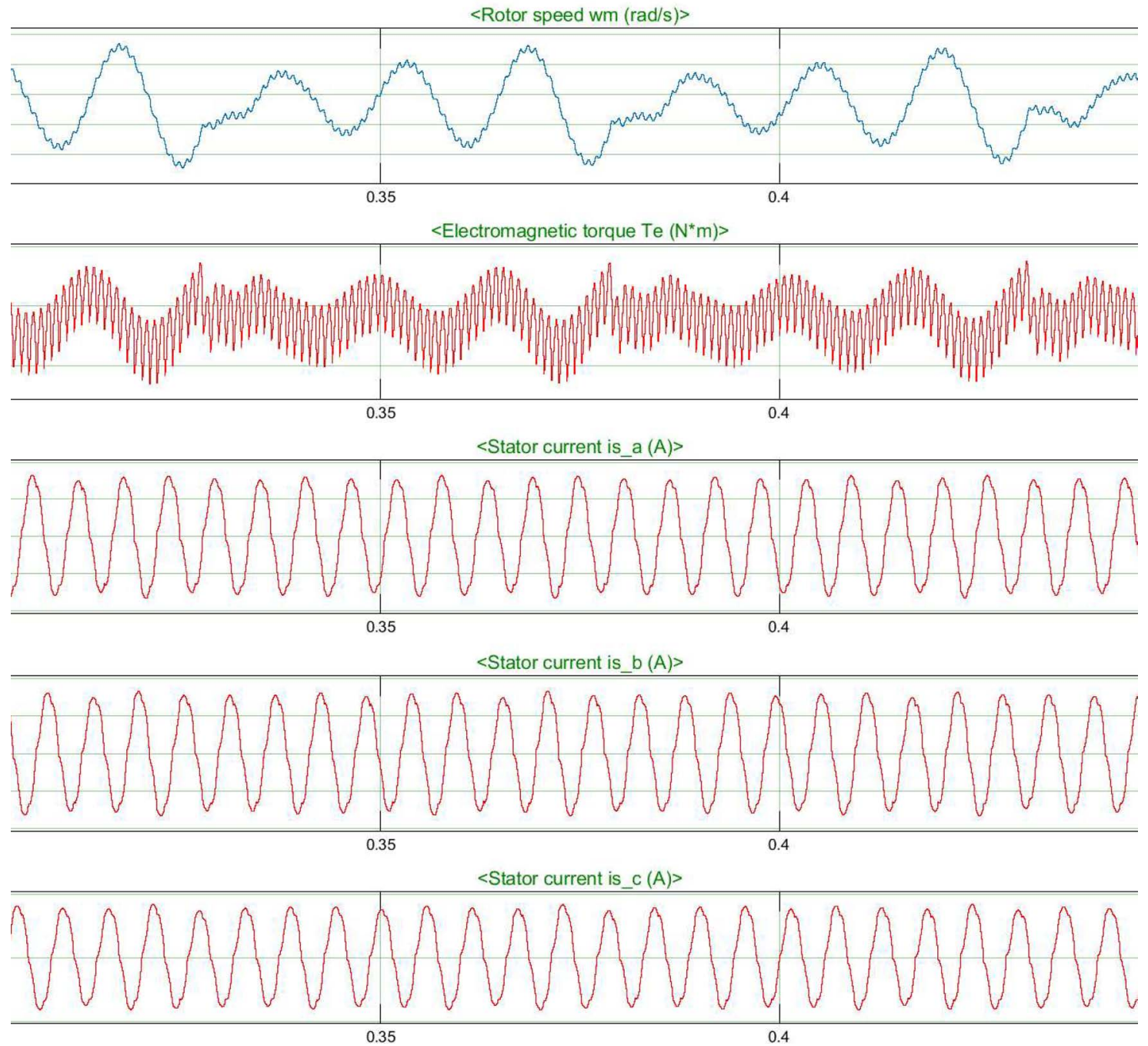

Figure 17. Rotor speed, torque and rotor currents. 


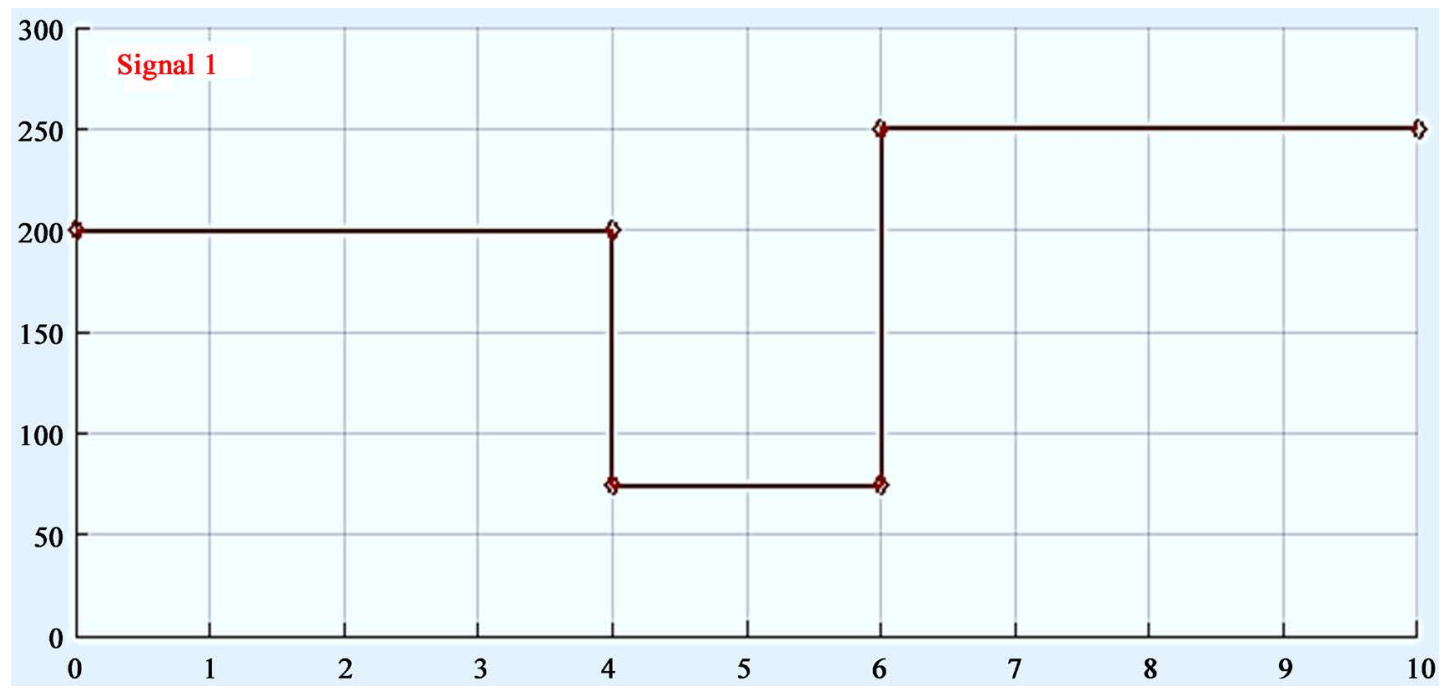

Figure 18. Source characteristic.

\subsubsection{Battery SOC, Current and Voltage}

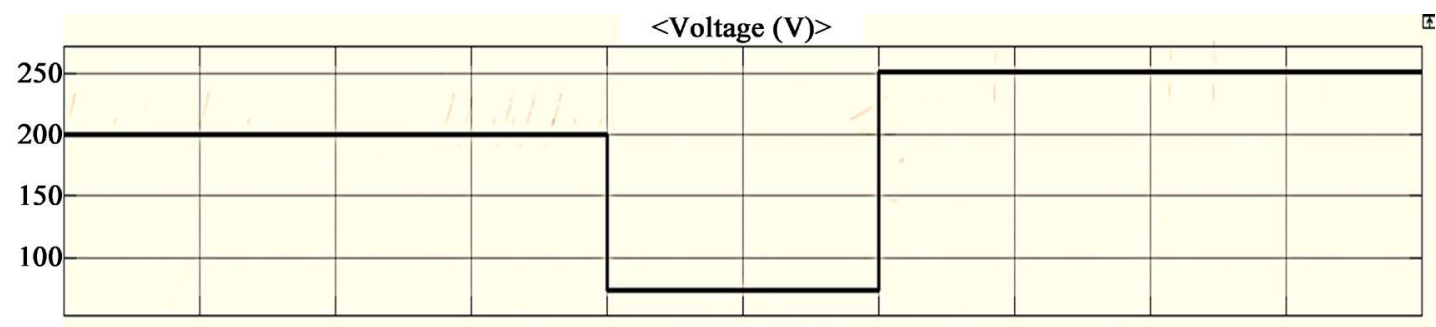

$<$ SOC (\%) $>$
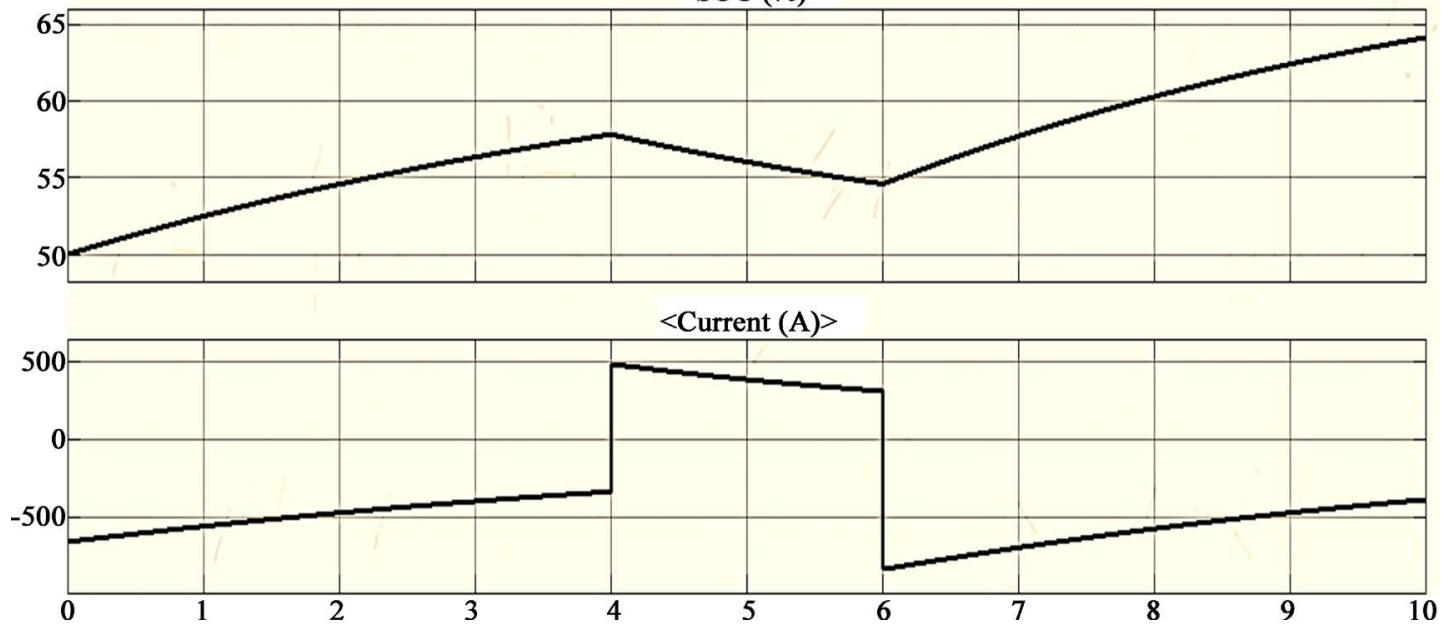

Figure 19. SOC, voltage and Current.

From 0 to $4 \mathrm{~s}$ and from $6 \mathrm{~s}$ to $10 \mathrm{~s}$, the battery charges.

From $4 \mathrm{~s}$ to $10 \mathrm{~s}$, the battery discharges (see Figure 19).

We can conclude at the state of charge, the shape of SOC is linearly increasing and remains decreasing at the state of discharge. The course of the current follows the course of the charge and discharge.

The voltage shape is at the rising edge if the battery is charging and the falling 


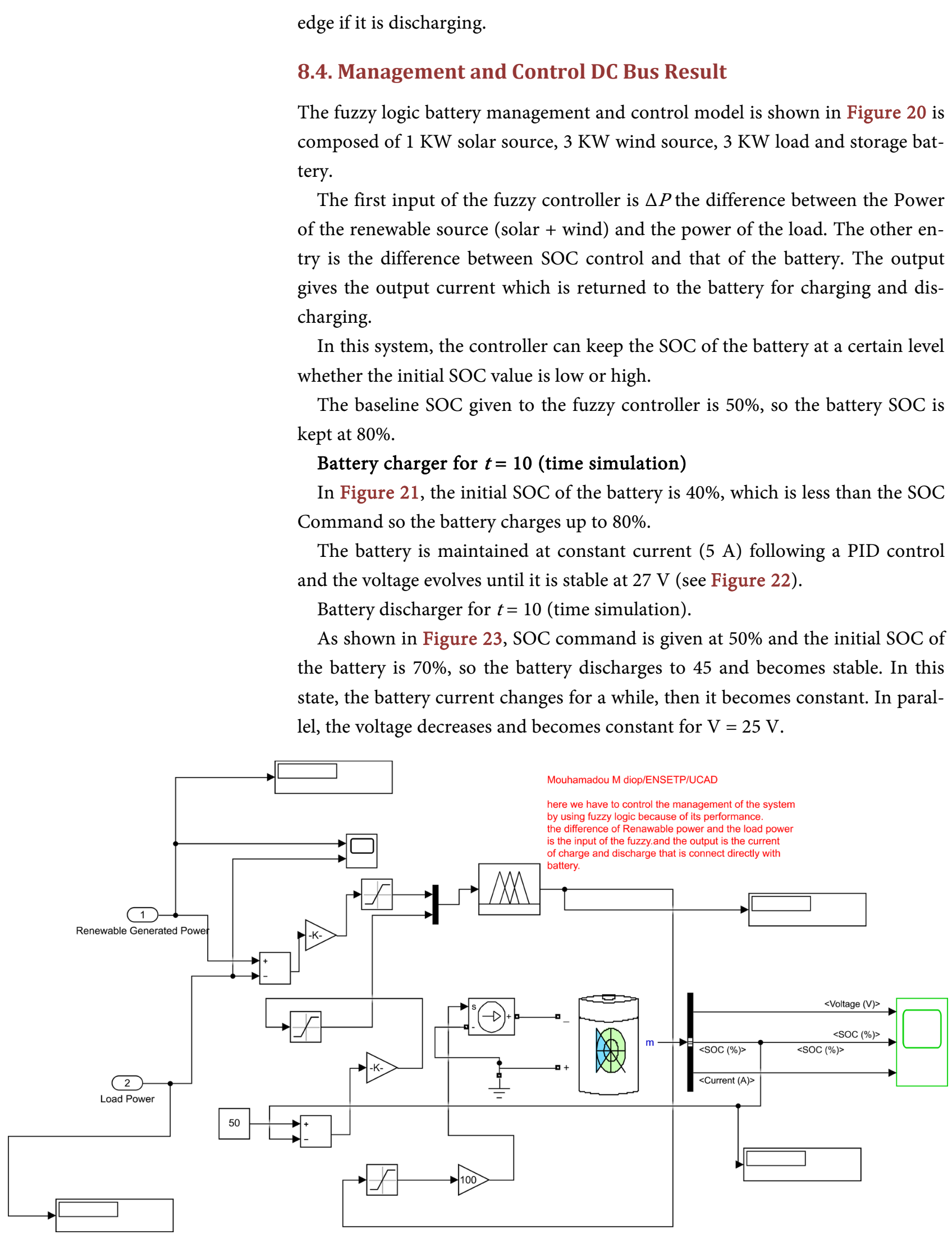

Figure 20. Simulation model of management and control battery with fuzzy Controller. 

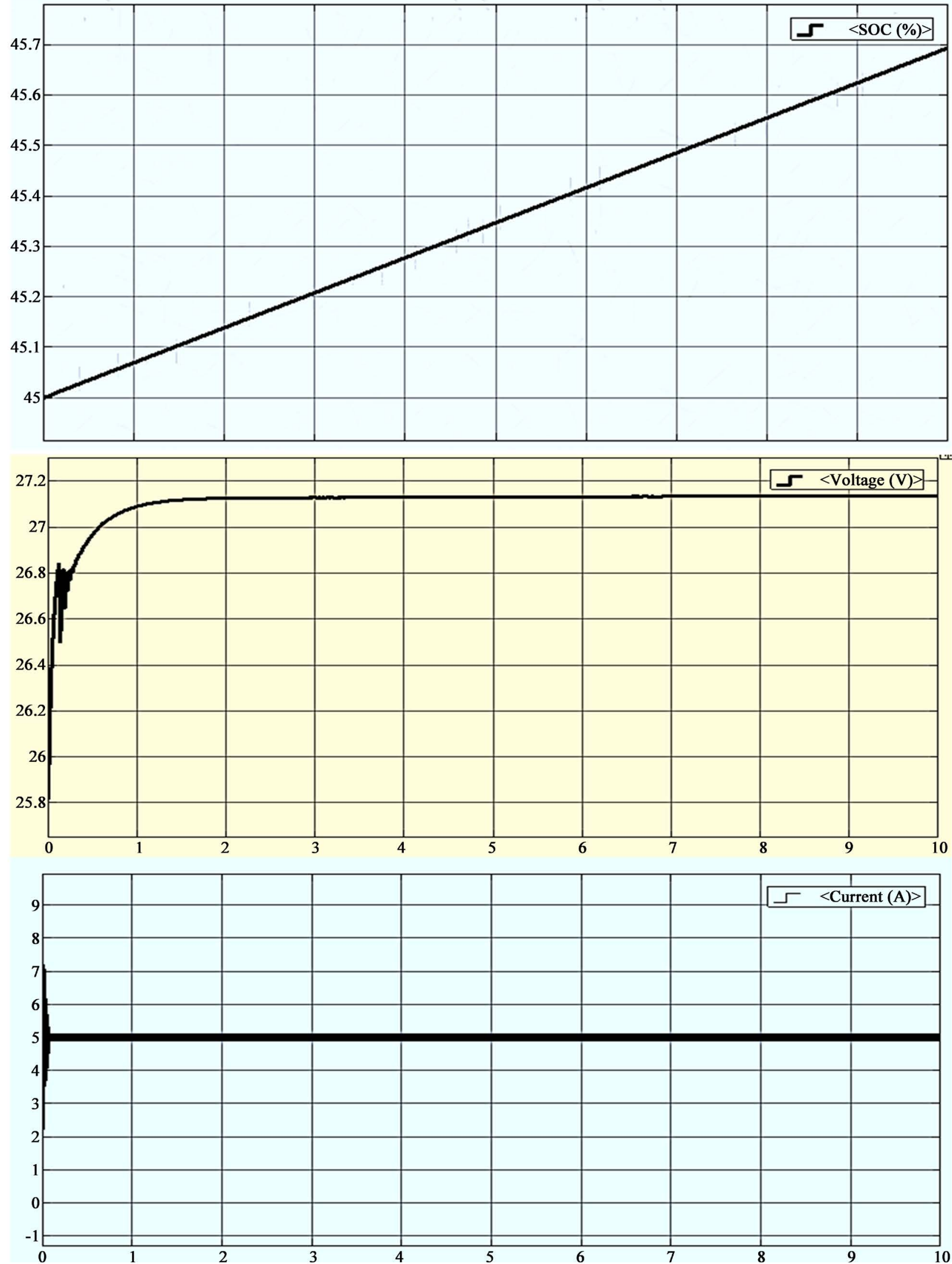

Figure 21. SOC less than 50\%. 


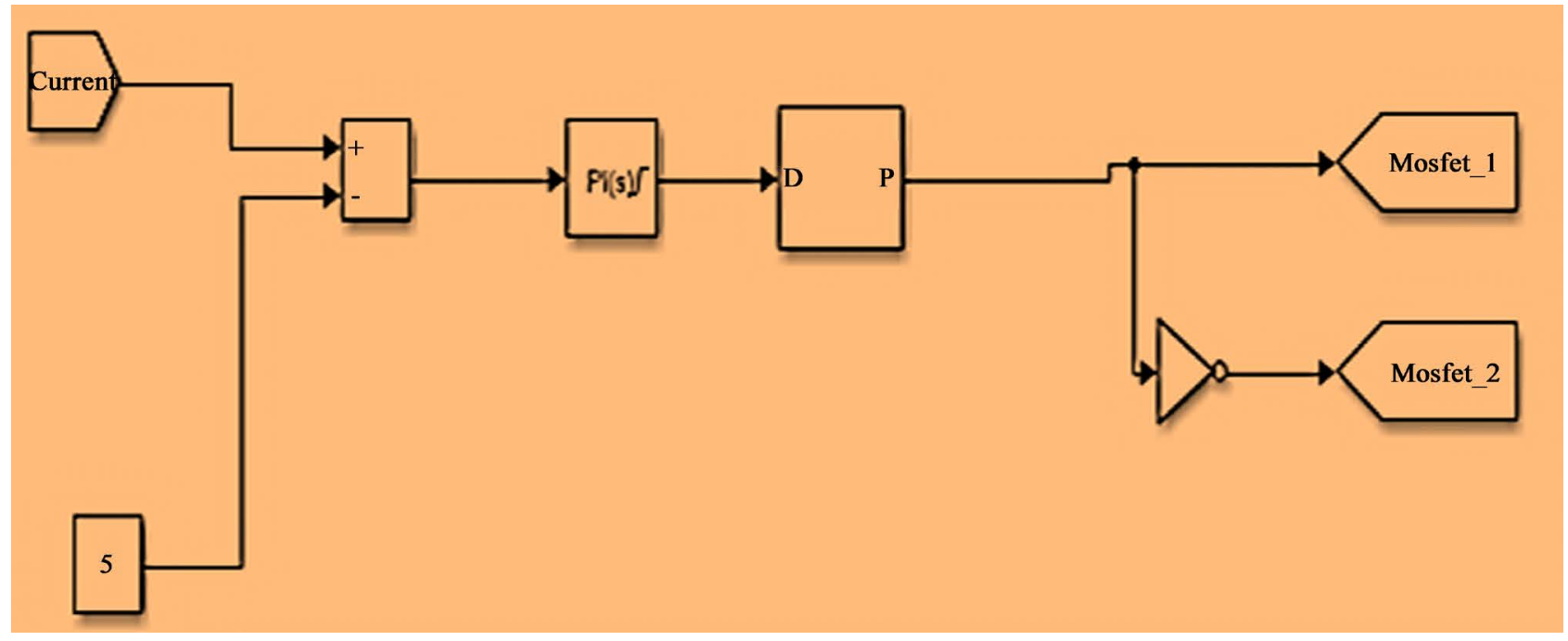

Figure 22. Current constant control.
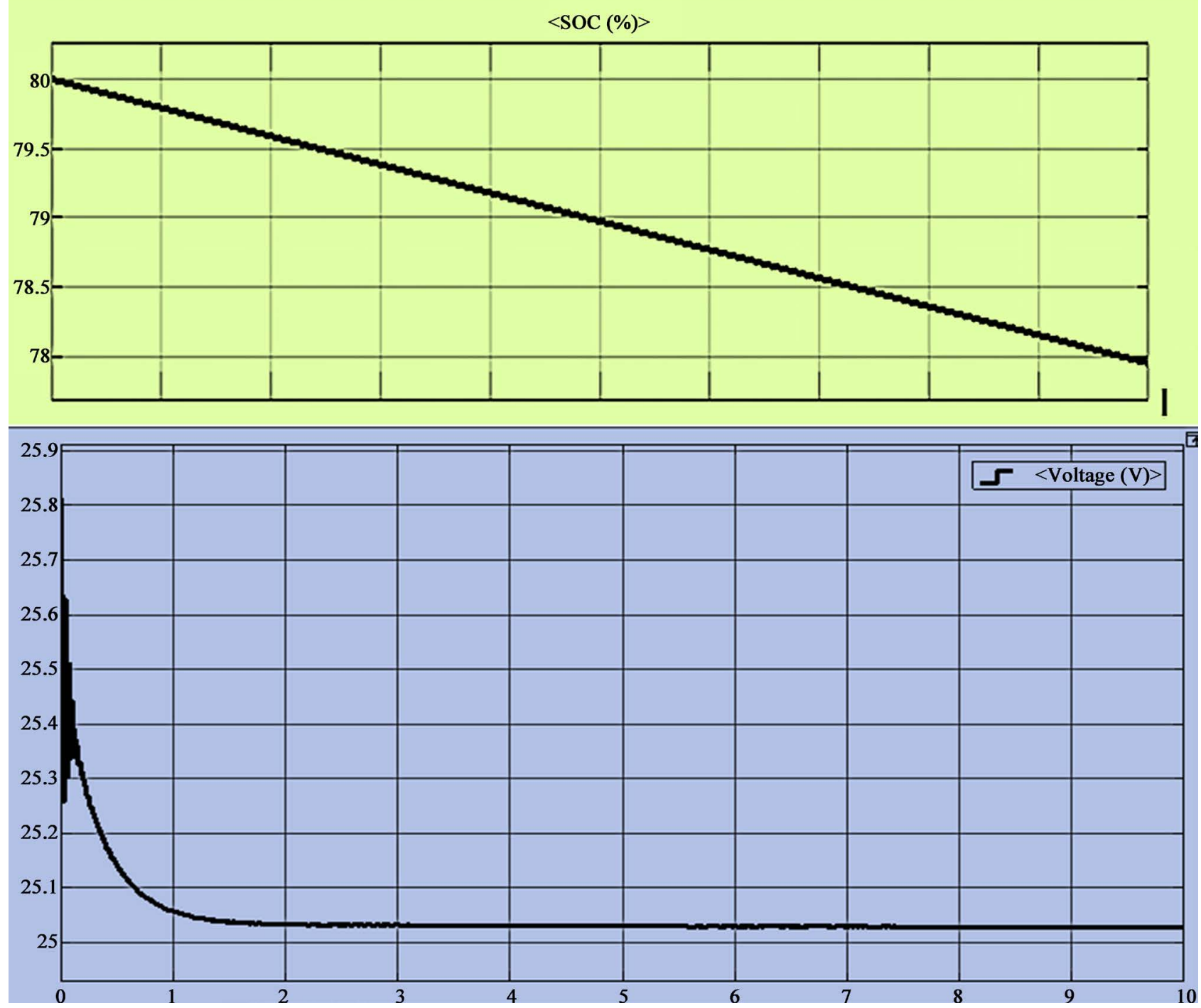

Figure 23. SOC more than 50\%. 


\subsection{Load Speed}

Réf and actual speed

The speed of the load (in blue) clearly follows the speed of the chosen reference (Figure 24).
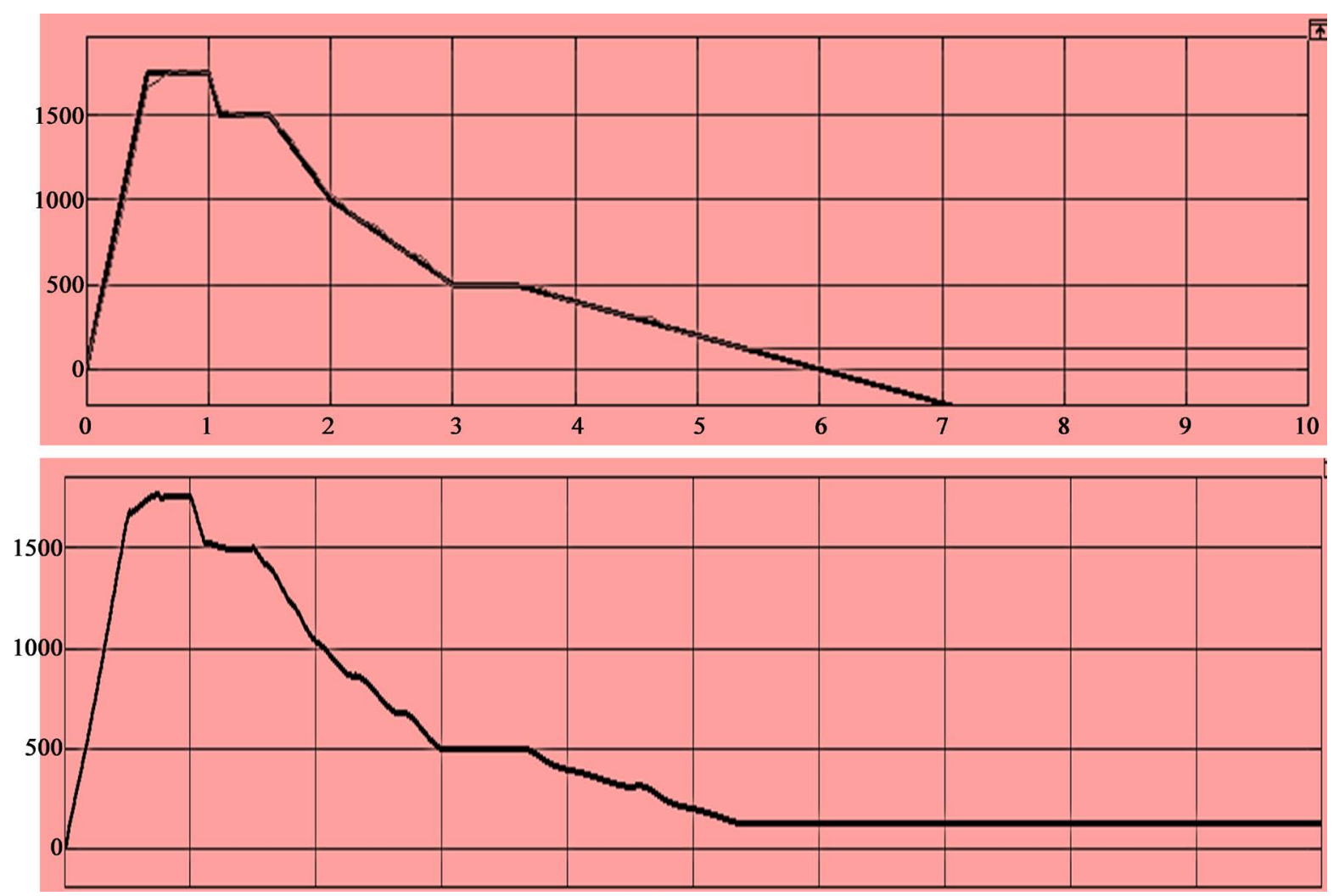

Figure 24. Load speed.

\section{Conclusion}

In this article, we have presented the control and management of a continuous BUS using fuzzy logic control to achieve the optimization of this system. According to the results, the SOC battery maintains the desired value to increase battery life by using fuzzy control rules and also saves excess electricity production from solar panels and wind turbines.

\section{Acknowledgements}

\section{Dr. Moustapha DIOP}

My research director, he followed the work with attention according to his availability.

\section{Dr. Ibrahima Gueye}

Head of the electrical engineering department at ENSETP, he contributed with his skills and advice.

\section{Dr. Abdoulaye Kebé}

Director of ENSETP, he contributed with his advice and support. 


\section{Conflicts of Interest}

The authors declare no conflicts of interest regarding the publication of this paper.

\section{References}

[1] Chiradeja, P. and Ramakumar, R. (2004) An Approach to Quantify the Technical Benefits of Distributed Generation. IEEE Transactions on Energy Conversion, 19, 764-773. https://doi.org/10.1109/TEC.2004.827704

[2] Nehrir, M.H., Wang, C., Strunz, K., Aki, H., Ramakumar, R., Bing, J., Miao, Z. and Salameh, Z. (2011) A Review of Hybrid Renewable/Alternative Energy Systems for Electric Power Generation: Configurations, Control, and Applications. IEEE Transactions on Sustainable Energy, 2, 392-403. https://doi.org/10.1109/TSTE.2011.2157540

[3] Tant, J., Geth, F., Six, D. and Tant, P. (2013) Multiobjective Battery Storage to Improve PV Integration in Residential Distribution Grids. IEEE Transactions on Sustainable Energy, 4, 182-191. https://doi.org/10.1109/TSTE.2012.2211387

[4] Yin, Y., Luo, X., Guo, S., Zhou, Z.D. and Wang, J.H. (2008) A Battery Charging Control Strategy for Renewable Energy Generation Systems. Proceedings of the World Congress on Engineering, London, 2-4.

[5] Mirecki, A. (2005) Etude comparative de chaine de conversion d'énergie dédiée à une éolienne de petite puissance. Thèse de doctorat de l'institut nationale polytechniques de Toulouse, France.

[6] Khettache, L. (2007) Etude et commande d'un système éolien à base d'une machine électrique Double alimentée. Mémoire de Magistère en électrotechnique Université de Batna.

[7] Tech, K.H.M. (2014) Battery Energy Management System for DC Micro Grids with Fuzzy Controller. International Journal of Innovative Science, Engineering and Technology, 3, 1486-1493. 